\title{
Application of Levenberg-Marquardt Optimization Algorithm Based Multilayer Neural Networks for Hydrological Time Series Modeling
}

\author{
Umut Okkan $^{a}$ \\ ${ }^{a}$ Department of Civil Engineering, Balikesir University-Turkey \\ Email: umutokkan@balikesir.edu.tr
}

(Received March 03, 2011; in final form June 24, 2011)

\begin{abstract}
Recently, Artificial Neural Networks (ANN), which is mathematical modeling tools inspired by the properties of the biological neural system, has been typically used in the studies of hydrological time series modeling. These modeling studies generally include the standart feed forward backpropagation (FFBP) algorithms such as gradient-descent, gradient-descent with momentum rate and, conjugate gradient etc. As the standart FFBP algorithms have some disadvantages relating to the time requirement and slow convergency in training, Newton and Levenberg-Marquardt algorithms, which are alternative approaches to standart FFBP algorithms, were improved and also used in the applications. In this study, an application of Levenberg-Marquardt algorithm based ANN (LM-ANN) for the modeling of monthly inflows of Demirkopru Dam, which is located in the Gediz basin, was presented. The LM-ANN results were also compared with gradientdescent with momentum rate algorithm based FFBP model (GDM-ANN). When the statistics of the long-term and also seasonal-term outputs are compared, it can be seen that the LM-ANN model that has been developed, is more sensitive for prediction of the inflows. In addition, LM-ANN approach can be used for modeling of other hydrological components in terms of a rapid assessment and its robustness.
\end{abstract}

Keywords: Levenberg-Marquardt optimization algorithm, Artificial neural networks, Hydrological time series modeling

\section{AMS subject classifications: $92 \mathrm{~B} 20,62 \mathrm{M} 10$}

\section{Introduction}

The application of water resource engineering methods to evaluate the potential of water resource and the decision making strategies of water resource management, such as droughtflood analysis, irrigation, reservoir performances based on probability of failure and, the development of integrated river basin models under the certain climate scenarios, needs the forecasting of streamflow data and modeling of rainfall-runoff relations. In this context, the examination of hydrological processes and causalities of these processes deepens our understanding of modeling. Especially, the recent and apparent impacts of climate change have also popularized these models.

Corresponding Author. Email: umutokkan@balikesir.edu.tr
A basin can be considered as a system that transforms the rainfall to runoff. The modeling of this system can be set up to obtain the relation of the transformation by making simplifying assumptions because a basin has very complicated and uncertain components. There are different classifications presented in the literature to qualify basin models which include system definitions, area-time scales and solution techniques. But in general, there are three main approaches in representing the basin systems: white-box models (physical based distributed models), the gray-box models (conceptual models) and the blackbox models [1]. The white and gray-box models aim to simulate physical creation mechanism in the ways of each of theirs components, such as surface, subsurface and groundwater flow, infiltration, percolation, and 
evapotranspiration. The relevant parameters of these components for a certain basin are determined by different optimization techniques. However, in terms of uncertainties, data requirements and complexities of model parameters, they can not use in some applications. Because of uncertainties and complexities in these modeling studies, the basin may be also considered as the black-box models which are applied to associate basin inputs and desired outputs without detailed consideration about the physical processes of the phenomena. In this context, conventional statistical models are commonly used in applications which contain regression analyses, curve fitting approaches and stochastic autoregressive models [2-9]. In addition to these, artificial neural networks (ANNs) are also employed to streamflow modeling [10-15]. The ANNs can be considered as complex and nonlinear regression models structured between basin inputs (precipitation, temperature, evaporation etc.) and basin output "streamflow" data. Although there are several ANN techniques, feed forward backpropagation (FFBP) algorithm based models used in applications typically. A number of ANN studies have been reported in literature. Some of them are given. Minns and Hall (1996) prepared a FFBBP algorithm based ANN model by using synthetic data set to forecast streamflows. Campalo et al.(1999) developed an ANN model to analyze and forecast the behavior of the river Tagliamento, in Italy [16]. Mendez et al. (2004), Kisi (2005) and Okkan and Mollamahmutoglu (2010a) investigated the performance of ANN and autoregressive models in prediction of streamflow $[15,17,18]$. They were shown that ANN methods yielded better results than autoregressive models. Cigizoglu (2003) also used an autoregressive model which was employed to generate synthetic monthly flows [14]. These generated values were used as the training sets of ANNs to forecast the observed Goksu River monthly mean flows in the East Mediterranean part of Turkey. According to this, the forecasting results were compared with the ANN performance when only a limited number of observed flows were employed in the training data sets. Increasing the data sets in the training stage improved the forecasting performance significantly. In addition to FFBP algorithms, Generalized Regression Neural Networks [19, 20] and Radial Basis Neural Networks [21-23] studies were also used in streamflow predictions. Briefly, all of these studies shown that the ANN is probably the most successful black box tool which is capable of modeling complex and uncertain relationships between input and output variables without the detailing of the physical process.

In the study presented, an application of Levenberg-Marquardt algorithm based ANN (LM-ANN) for the modeling of monthly inflows of Demirkopru Dam, which is located in the Gediz Basin, was presented. The LM-ANN results were also compared with gradient-descent with momentum rate algorithm based FFBP model (GDM-ANN).

\section{The Multilayer Neural Networks}

The basic concept of the multilayer neural networks is that they are typically made up of single neurons. And in the multilayer neural networks, the neurons are organized in the form of layers (Figure 1).

The first and last layer of multilayer neural networks is called the input and the output layers respectively.The input layer does not perform any computations, but only serves to feed the input data to the hidden layer which is between the input and output layers.

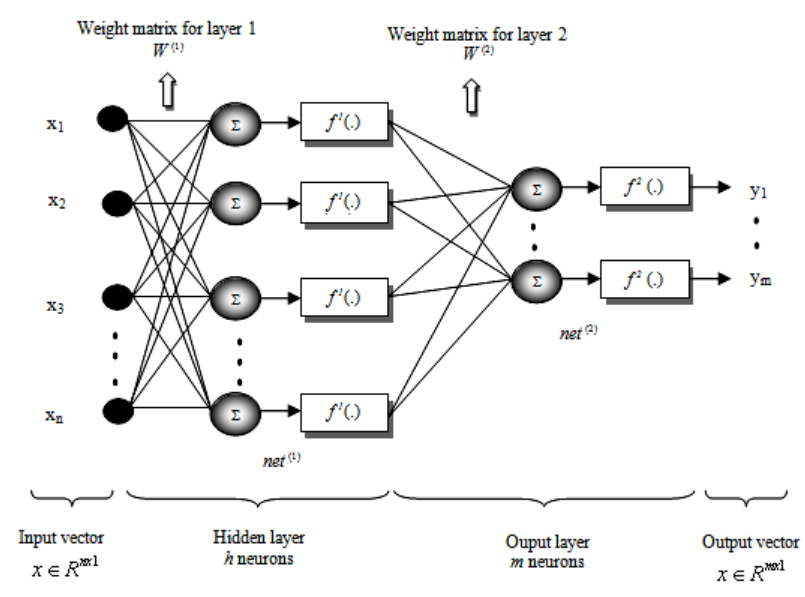

Figure 1. A multilayer neural network structure [18]

In general, there can be any number of hidden layers in the multilayer neural networks structures. However, from practical applications, only one or two hidden layers are used. In addition to this, the number of hidden layers and also the number of neurons of hidden layers can be determined by trial and error [24-26].

There are also three important components of a multilayer neural network structure: weights, summing function and activation function. The importance and functionality of the inputs on 
neural network models are obtained with weights $(W)$.

So the success of the model depends on the precise and correct determination of weight values. The summing function (net) acts to add all outputs; that is, each neuron input is multiplied by the weights and then summed. After computing the sum of weighted inputs for all neurons, the activation function $f($.) serves to limit the amplitude of these values. The activation functions are usually continuous, nondecreasing and bounded functions.

Various types of the activation function are possible but generally sigmoid function is preferred in applications [26]. This activation function generates outputs between 0 and 1 as the input signal goes from negative to positive infinity.

$$
f(.) \cong \frac{1}{1+e^{-(.)}}
$$

In addition to the structure and its components of multilayer neural networks, the running procedure is also important which involves typically two phases; forward computing and backward computing.

In forward computing, each layer uses a weight matrix $\left(W^{(v)}\right.$, for $\left.v=1,2\right)$ associated with all the connections made from the previous layer to the next layer (Figure 1). The hidden layer has the weight matrix $W^{(1)} \in R^{h x n}$, the output layer's weight matrix is $W^{(2)} \in R^{m \times h}$. Given the network input vector $x \in R^{n x 1}$, the output of the hidden layer $x_{\text {out }, 1} \in R^{h x 1}$ can be written as

$$
x_{\text {out }, 1}=f^{(1)}\left[n e t^{(1)}\right]=f^{(1)}\left[W^{(1)} x\right]
$$

which is the input to the output layer. The output of the output layer, which is the response (output) of the network $y=x_{\text {out }, 2} \in R^{m x 1}$, can be written as

$$
y=x_{\text {out }, 2}=f^{(2)}\left[n e t^{(2)}\right]=f^{(2)}\left[W^{(2)} x_{\text {out }, 1}\right]
$$

Substituting (Eq.2) into (Eq.3) for $\mathrm{x}_{\text {out, } 1}$ gives the final output $y=x_{\text {out }, 2}$ of the network as

$$
y=f^{(2)}\left[W^{(2)} f^{(1)}\left[W^{(1)} x\right]\right]
$$

After the phase of forward computing, backward computing which depending on the algorithms to adjust weights is used in the multilayer neural networks. The process of adjusting these weights to minimize the differences between the actual and the desired output values is called training or learning the network. If these differences (error) are higher than the desired values, the errors are passed backwards through the weights of the network. In ANN terminology, this phase is also called the backpropagation algorithm. Once the comparison error is reduced to an acceptable level for the whole training set, the training period ends, and the network is also tested for another known input and output data set in order to evaluate the generalization capability of the ANN [24, 26].

Depending on the techniques to train ANN models, different back propagation algorithms have been developed. In this study, the Levenberg-Marquardt algorithm (LM-ANN) was used for training of the network. The LevenbergMarquardt algorithm is a second order nonlinear optimization technique that is usually faster and more reliable than any other standart back propagation techniques [27-29] and it is similar to Newton's method [30,31].

\section{The Levenberg-Marquardt Algorithm}

The Levenberg-Marquardt optimization algorithm represents a simplified version of Newton's method [31] applied to the training multilayer neural networks [30, 32]. Consider the multilayer neural network shown in Figure 1, the running of the network training can be viewed as finding a set of weights that minimized the error $\left(e_{p}\right)$ for all samples in the training set $(Q)$. If the performances function is a sum of squares of the errors as

$$
E(W)=\frac{1}{2} \sum_{p=1}^{P}\left(d_{p}-y_{p}\right)^{2}=\frac{1}{2} \sum_{p=1}^{P}\left(e_{p}\right)^{2}, P=m Q
$$

where $Q$ is the total number of training samples, $m$ is the number of output layer neurons, $W$ represents the vector containing all the weights in the network, $y_{p}$ is the network output, and $d_{p}$ is the desired output.

When training with the Levenberg-Marquardt optimization algorithm, the changing of weights $\Delta W$ can be computed as follows

$$
\Delta W=-\left[J_{k}^{T} J_{k}+\mu_{k} I\right]^{-1} J_{k}^{T} e_{k}
$$

where $\boldsymbol{J}$ is the Jacobian. matrix, $I$ is the identify matrix, $\boldsymbol{\mu}$ is the Marquardt parameter which is to be updated using the decay rate $\beta$ depending on the outcome. In particular, $\boldsymbol{\mu}$ is multiplied by the decay rate $\beta(0<\beta<1)$ whenever $\boldsymbol{E}(\boldsymbol{W})$ decreases, while $\mu$ is divided by $\beta$ whenever $\boldsymbol{E}(\boldsymbol{W})$ increases in a new step $(k)$.

The LM-ANN training process can be illustrated in the following pseudo-codes, 
1. Initialize the weights and $\mu(\mu=0.001$ is appropriate).

2. Compute the sum of squared errors over all inputs, $\boldsymbol{E}(\boldsymbol{W})$.

3. Compute the Jacobian matrix $\boldsymbol{J}$.

4. Solve Eq.6 to obtain the changing of weights $\Delta W$.

5. Recompute the sum of squared errors $\boldsymbol{E}(\boldsymbol{W})$ using $W_{(k+1)}=W_{k}-\left[J_{k}^{T} J_{k}+\mu_{k} I\right]^{-1} J_{k}^{T} e_{k}$ as the trial $\boldsymbol{W}$, and judge

IF trial $\boldsymbol{E}(\boldsymbol{W})<\boldsymbol{E}(\boldsymbol{W})$ in Step 2, THEN

$$
\begin{aligned}
& W_{(k+1)}=W_{k}-\left[J_{k}^{T} J_{k}+\mu_{k} I\right]^{-1} J_{k}^{T} e_{k} \\
& \mu_{(k+1)}=\mu_{k} \beta \quad(\beta=0.1)
\end{aligned}
$$

ELSE

go back to Step 2.

$$
\mu_{(k+1)}=\mu_{k} / \beta
$$

END IF

go back to Step 4.

\section{Application}

The application area covers the Demirkopru Dam's basin which is located in the Aegean region of Turkey. The study region has typical Mediterranean climate characteristics.

Demirkopru Dam's basin is also called the Upper Gediz which has four rivers (Demirci, Deliinis, Selendi and Murat) located upstream of the dam with a total drainage area of $6590 \mathrm{~km}^{2}$ (Figure 2).

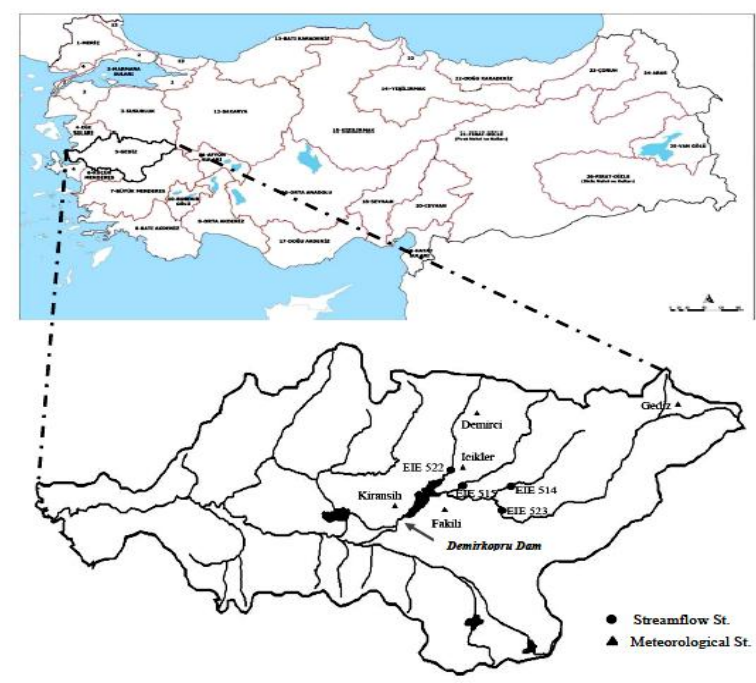

Figure 2 The streamflow and the meteorological stations in the study area

LM-ANN modeling was applied on the observed data of selected 5 meteorological stations and 4 streamflow gauging stations (Table 1).

Table 1 Selected meteorological and streamflow gauging stations in the study area

\begin{tabular}{lll}
\hline Type of Stations & Station Names & Station Numbers \\
\hline \multirow{3}{*}{ Meteorological } & Demirci & DMI 17746 \\
& İcikler & DSI 05-018 \\
& Kiransih & DSI 05-016 \\
& Fakili & DSI 05-012 \\
& Gediz & DMI 17750 \\
\hline \multirow{3}{*}{ Streamflow } & Demirci & EIE 522 \\
& Deliinis & EIE 515 \\
& Selendi & EIE 514 \\
& Gediz & EIE 523 \\
\hline
\end{tabular}

For the study region, the monthly data set of streamflows $\left(10^{6} \mathrm{~m}^{3}\right)$ at each station was obtained from EIE (the General Directorate of Electrical Power Resources Survey and Development Administration of Turkey) and then summed. Thus, monthly inflows of Demirkopru dam was determined for the period from 1977 to 2006 . The monthly data sets of precipitation at Demirci, Icikler, Kiransih, Fakili and Gediz meteorological stations were obtained from DMI (the State Meteorological Organization of Turkey) and DSI (the General Directorate of State Hydraulic Works of Turkey) and the monthly mean areal precipitation values determined from these meteorological stations by using Thiessen polygons. The monthly data sets of temperature at Demirci and Gediz meteorological stations were also obtained from DMI (the State Meteorological Organization of Turkey) and the monthly mean areal temperature values computed by using arithmetical mean values from these meteorological stations for the period from January 1977 to December 2006.

In the modeling application, 30 years (January 1977-December 2006) input-output data were used and divided into training and testing periods by proportions of 2/3 (January 1977- December 1996) and 1/3 (January 1997-December 2006), respectively. Before presenting the input-output data to ANN, the all data set were scaled to the range $0-1$ so that the different input signal had the same numerical range. The training and the testing subsets were scaled to the range of $0-1$ using the equation $\mathrm{z}_{\mathrm{t}}=\left(\mathrm{x}_{\mathrm{t}}-\mathrm{x}_{\min }\right) /\left(\mathrm{x}_{\max }-\mathrm{x}_{\min }\right)$, where $\mathrm{x}_{\mathrm{t}}$ is the unscaled data, $\mathrm{z}_{\mathrm{t}}$ is scaled data, and $\mathrm{x}_{\max }$ and $x_{\min }$ are the maximum and minimum values 
of the unscaled data, respectively. Then, the output values of the networks, which were in the range of $0-1$, were converted to real-scaled values using the equation $\mathrm{x}_{\mathrm{t}}=\mathrm{z}_{\mathrm{t}}\left(\mathrm{x}_{\max }-\mathrm{x}_{\min }\right)+\mathrm{x}_{\text {min }}$. Because of the scaling range, the sigmoid function was selected as the activation function which generates outputs between 0 and 1 .

In training, the number of hidden layers, the number of the neurons in the hidden layers and Marquardt parameters were determined after trying various network structures. The network structure providing the best result, i.e., the minimum root mean square errors, RMSE (Eq. 7), and the maximum determination coefficients, $R^{2}$ (Eq. 8) was also employed for the testing period.

$$
\begin{gathered}
R M S E=\sqrt{\frac{1}{T} \sum_{t=1}^{T}\left(d_{t}-y_{t}\right)^{2}} \\
R^{2}=\frac{\sum_{t=1}^{T}\left(d_{t}-d_{\text {mean }}\right)^{2}-\sum_{t=1}^{T}\left(d_{t}-y_{t}\right)^{2}}{\sum_{t=1}^{T}\left(d_{t}-d_{\text {mean }}\right)^{2}}
\end{gathered}
$$

where $T$ is the number of training or testing samples, $y_{t}$ is the network output, $d_{t}$ is the observed (desired) data in the $t^{\text {th }}$ time period, and $d_{\text {mean }}$ is the mean over the observed periods.

The modeling study started with the networkinput data consisting of the concurrent monthly rainfall and temperature and the corresponding inflows at Demirkopru Dam as an output from the network. The maximum possible model determinations $\left(R^{2}\right)$ and the minimum root mean square errors $(R M S E)$ obtained with two inputs and one output, network was $70.94 \%$ and 37.74 $\left(10^{6} \mathrm{~m}^{3}\right)$ and $61.17 \%$ and $46.09\left(10^{6} \mathrm{~m}^{3}\right)$ for the training and testing periods respectively. The number of neurons in the hidden layer was tried between 2 and 20 and the one with 12 neurons gave the best performance on the testing data. To develop the performance of the LM-ANN model, antecedent rainfalls were included in the input. The best performance for the model determinations was obtained with 9 neurons in the hidden layer with a concurrent monthly rainfall, temperature and three antecedent rainfalls used as input. With these inputs, determinations of $93.31 \%$ and $82.19 \%$ were obtained for the training and testing periods respectively. When two and three antecedent rainfalls were added to the model, the performance of training period improved, but in terms of root mean square errors, the performance for the testing period was found to be deteriorating. Thus, the model (Model I) which used concurrent rainfall, temperature and one antecedent rainfall as input was found to be sufficient and suitable than the others.

To improve the performance even further, it was required to use antecedent inflow values as input. According to this, the best performance (Model II) was obtained using one antecedent inflow, in addition to the concurrent rainfall, temperature and one antecedent rainfall, as input to the network. With these inputs and 3 neurons in the hidden layer, determinations of $93.74 \%$ and $84.16 \%$ and root mean square errors of $17.71\left(10^{6} \mathrm{~m}^{3}\right)$ and $25.77\left(10^{6} \mathrm{~m}^{3}\right)$ were obtained for the training and testing periods respectively. When two antecedent rainfalls were added to Model II, the performance for the testing period was also found to be deteriorating. The results of all of these experiments are summarized in Table 2. The best performances of the LM-ANN models (I and II) during the training and testing periods are shown in Figure 3 and Figure 4.

Table 2 The comparing of LM-ANN model performances with different inputs

\begin{tabular}{|c|c|c|c|c|c|}
\hline \multirow{2}{*}{ Inputs } & \multirow{2}{*}{$h$} & \multicolumn{2}{|c|}{$\begin{array}{l}\mathbf{R}^{2} \\
\%\end{array}$} & \multicolumn{2}{|c|}{$\begin{array}{l}\text { RMSE } \\
10^{6} \mathrm{~m}^{3}\end{array}$} \\
\hline & & Training & Testing & Training & Testing \\
\hline $\mathbf{R}_{t}-\mathbf{T}_{\mathbf{t}}$ & 12 & 70.94 & 61.17 & 37.74 & 46.09 \\
\hline $\begin{array}{l}\mathbf{R}_{\mathrm{t}}-\mathbf{T}_{\mathrm{t}}-\mathbf{R}_{\mathrm{t}-1} \\
(\text { Model I) }\end{array}$ & 3 & 79.17 & 75.34 & 31.95 & 34.37 \\
\hline $\begin{array}{l}\mathbf{R}_{\mathrm{t}}-\mathbf{T}_{\mathrm{t}}-\mathbf{R}_{\mathrm{t}-1}- \\
\mathbf{R}_{\mathrm{t}-2}\end{array}$ & 7 & 88.55 & 77.73 & 23.99 & 35.34 \\
\hline $\begin{array}{l}\mathbf{R}_{\mathrm{t}}-\mathbf{T}_{\mathrm{t}}-\mathbf{R}_{\mathrm{t}-1}- \\
\mathbf{R}_{\mathrm{t}-2}-\mathbf{R}_{\mathrm{t}-3}\end{array}$ & 9 & 93.31 & 82.19 & 18.13 & 36.49 \\
\hline $\begin{array}{l}\mathbf{R}_{\mathrm{t}}-\mathbf{T}_{\mathrm{t}}-\mathbf{R}_{\mathrm{t}-1}- \\
\mathbf{Q}_{\mathrm{t}-1} \\
\text { (Model II) }\end{array}$ & 3 & 93.74 & 84.16 & 17.71 & 25.77 \\
\hline $\begin{array}{l}R_{t}-T_{t}-R_{t-1^{-}} \\
Q_{t-1}-R_{t-2}\end{array}$ & 7 & 94.49 & 85.92 & 16.48 & 26.43 \\
\hline
\end{tabular}
$\left(\mu_{0}=0.001 ; \beta=0.1\right)$

(h: The number of neurons in the hidden layer; $\boldsymbol{R}:$ Rainfall; $\boldsymbol{T}$ : Temperature; Q: Inflow; (Model I): The best LM-ANN model which used the concurrent rainfall, temperature and one antecedent rainfall data as input; (Model II): The best LM-ANN model which used the concurrent rainfall, temperature, one antecedent rainfall and one antecedent inflow data as input.)

The results of suitable models are provided in Figure 5 as box-plots in order to compare the minimum, maximum and the median values of the observed and the predicted monthly inflows in the testing periods. Furthermore, the mean values of the observed and the predicted monthly inflows in the testing periods are also shown as a bar diagram in Figure 6. 
(a)
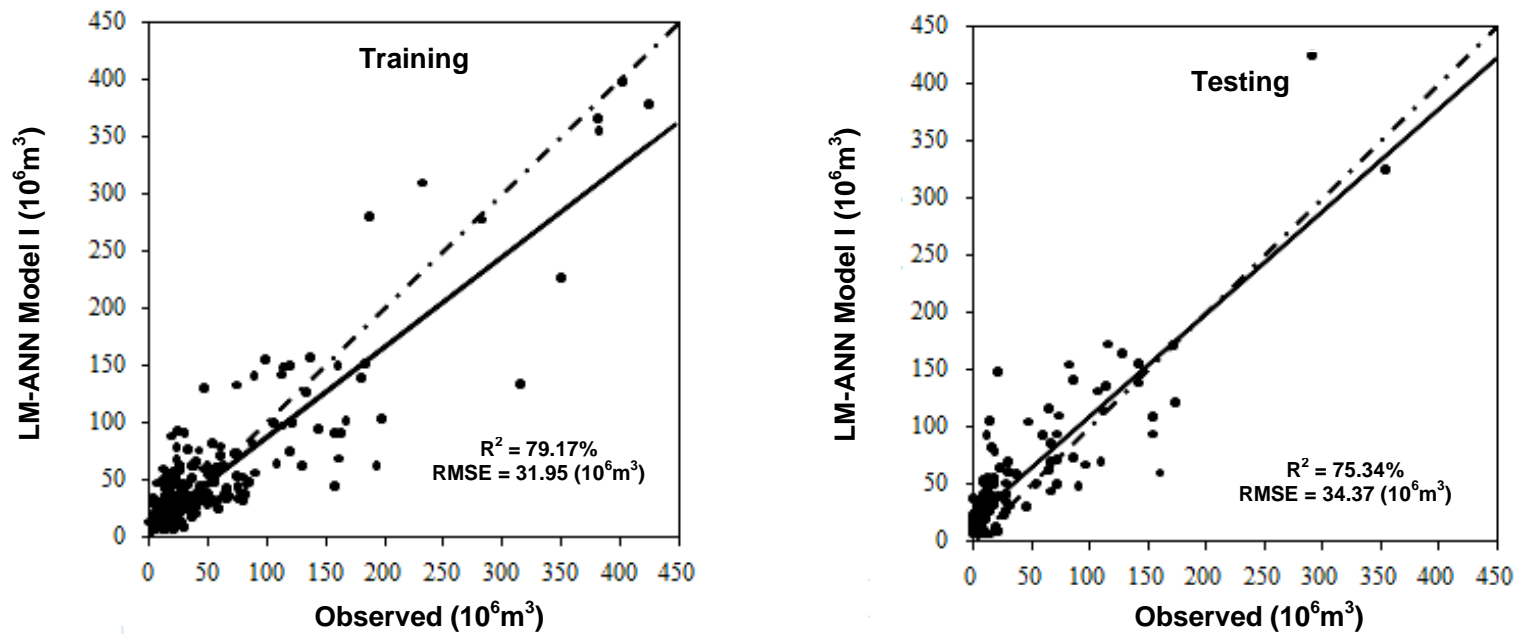

(b)
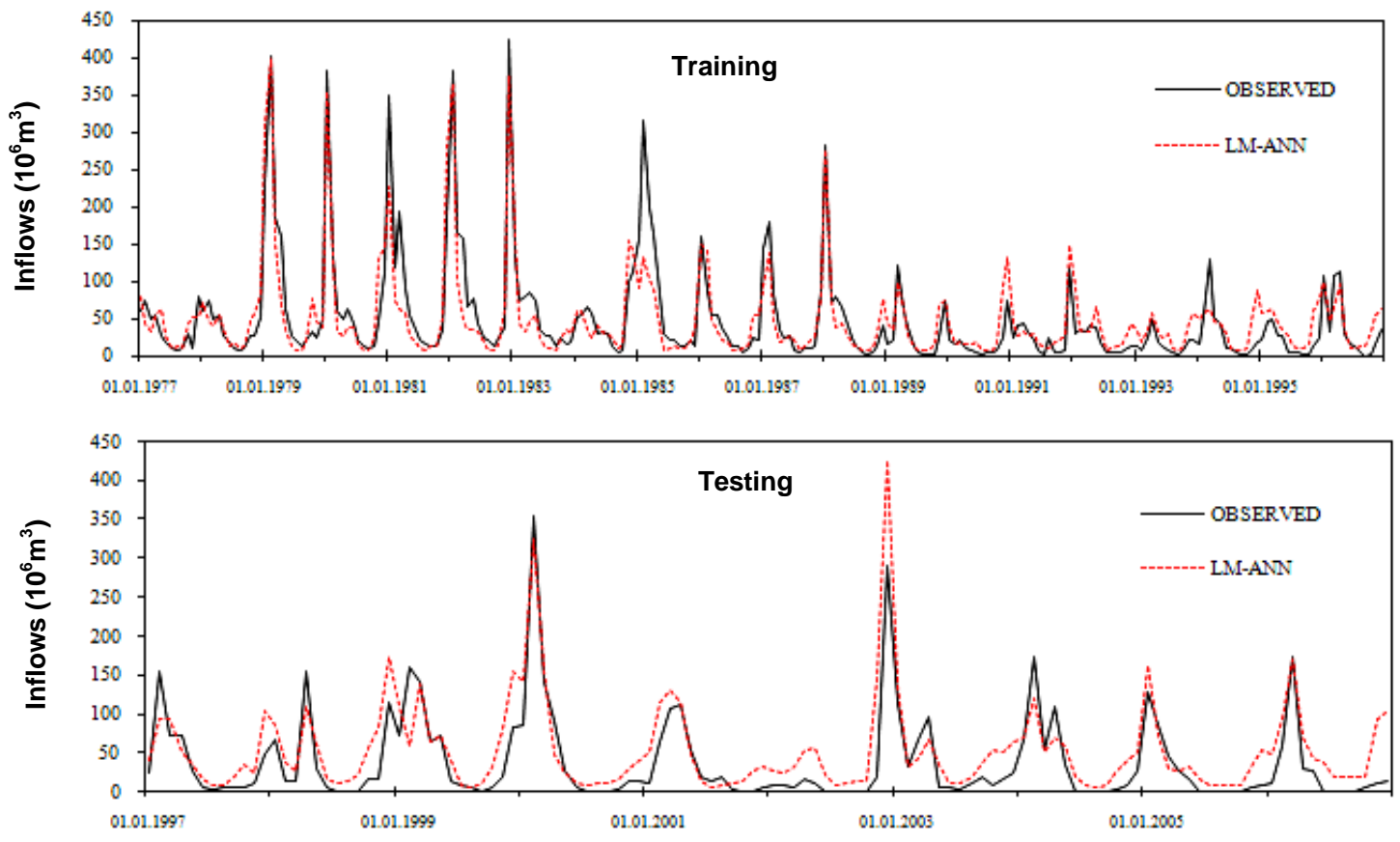

Figure 3 The scatter plots (a) and time series plots (b) of LM-ANN Model I which used the concurrent rainfall, temperature and one antecedent rainfall data as input $\left(\mu_{0}=0.001 ; \beta=0.1\right)$ 
(a)
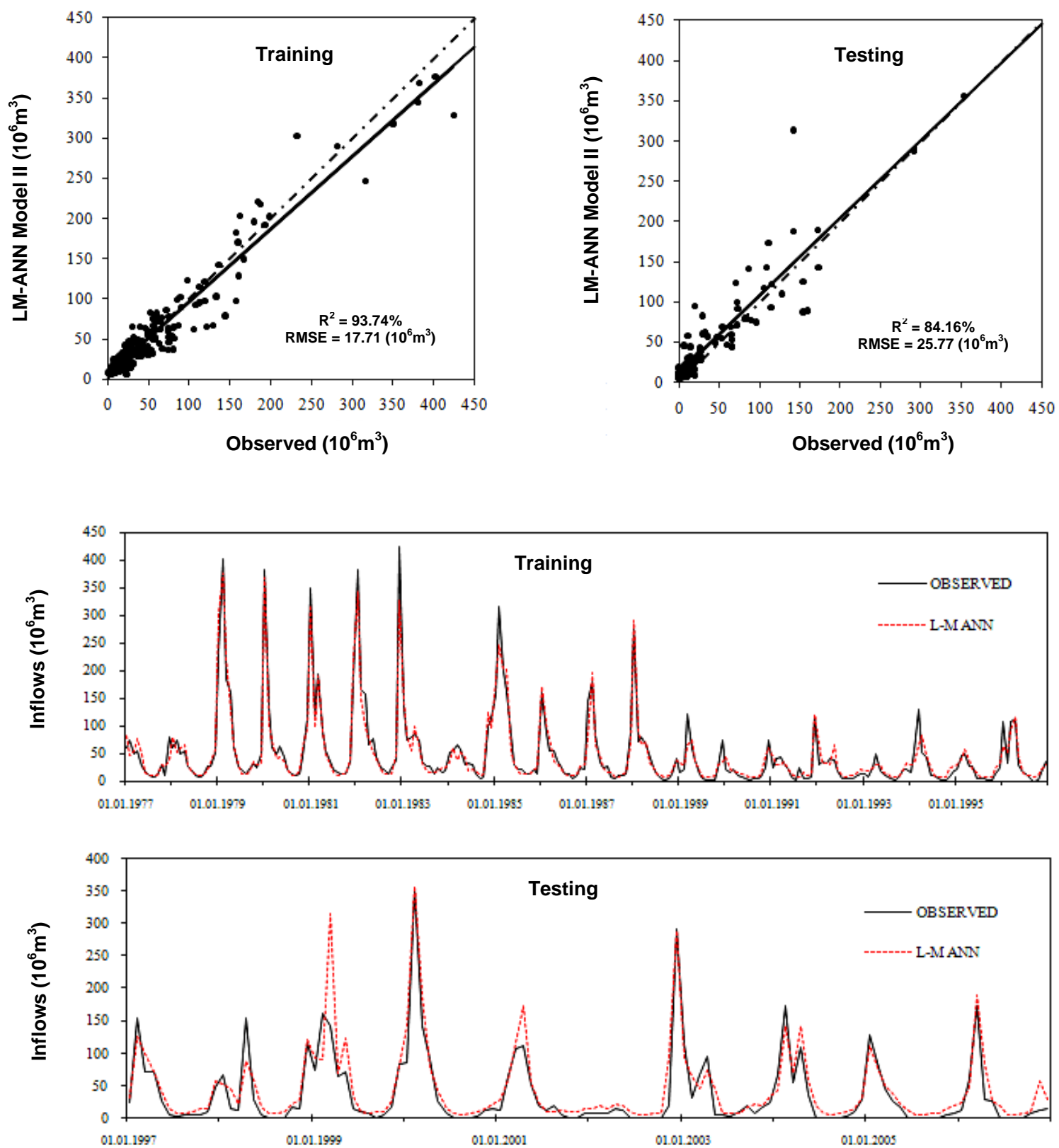

Figure 4. The scatter plots (a) and time series plots (b) of LM-ANN Model II which used the concurrent rainfall, temperature, one antecedent rainfall and one antecedent inflow data as input $\left(\mu_{0}=0.001 ; \beta=0.1\right)$ 
When the box-plots were examined, in terms of the median values of the observed and the predicted monthly inflows, the all models were fitted well. But the results of some months (especially November and December) in Model II which used the one antecedent inflow data as input was much better than the Model I.

When the box-plots were also compared, in terms of the extreme (maximum and minimum) values of the observed and the predicted monthly inflows, it was noticed that there were different results.
For example the extreme values of March were fitted by Model I. However, the results of November and December in Model II were much better than the Model I as well as in terms of monthly means (See Figure 6).

In the study, LM-ANN Model I results were also compared by using gradient-descent with momentum rate algorithm based FFBP approach (GDM-ANN). The best performance of GDMANN model was determined with 3 neurons in the hidden layer. By using the same inputs as Model I, the determinations of $73.12 \%$ and 62.20 $\%$ were computed for the training and testing periods respectively (See Figure 7).
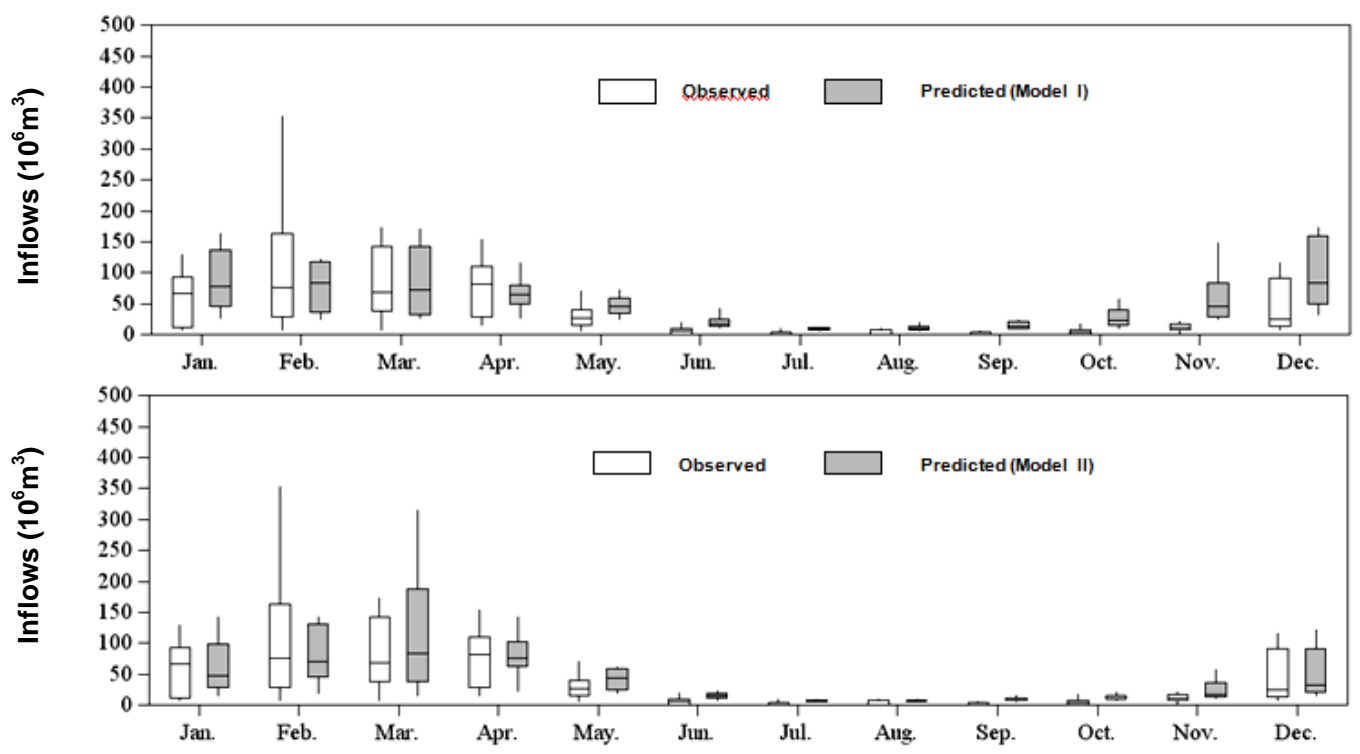

Figure 5 Box-plots of the observed and the predicted monthly inflows of Model I-II in the testing periods.

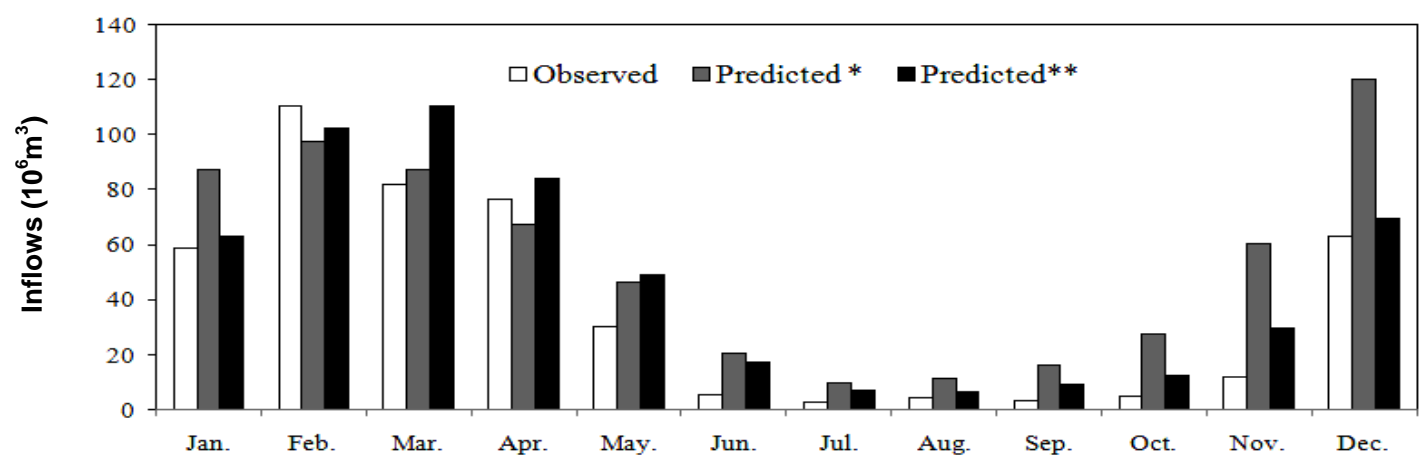

Figure 6 Bar diagram of the observed and the predicted monthly mean inflows for the testing periods. 
(a)
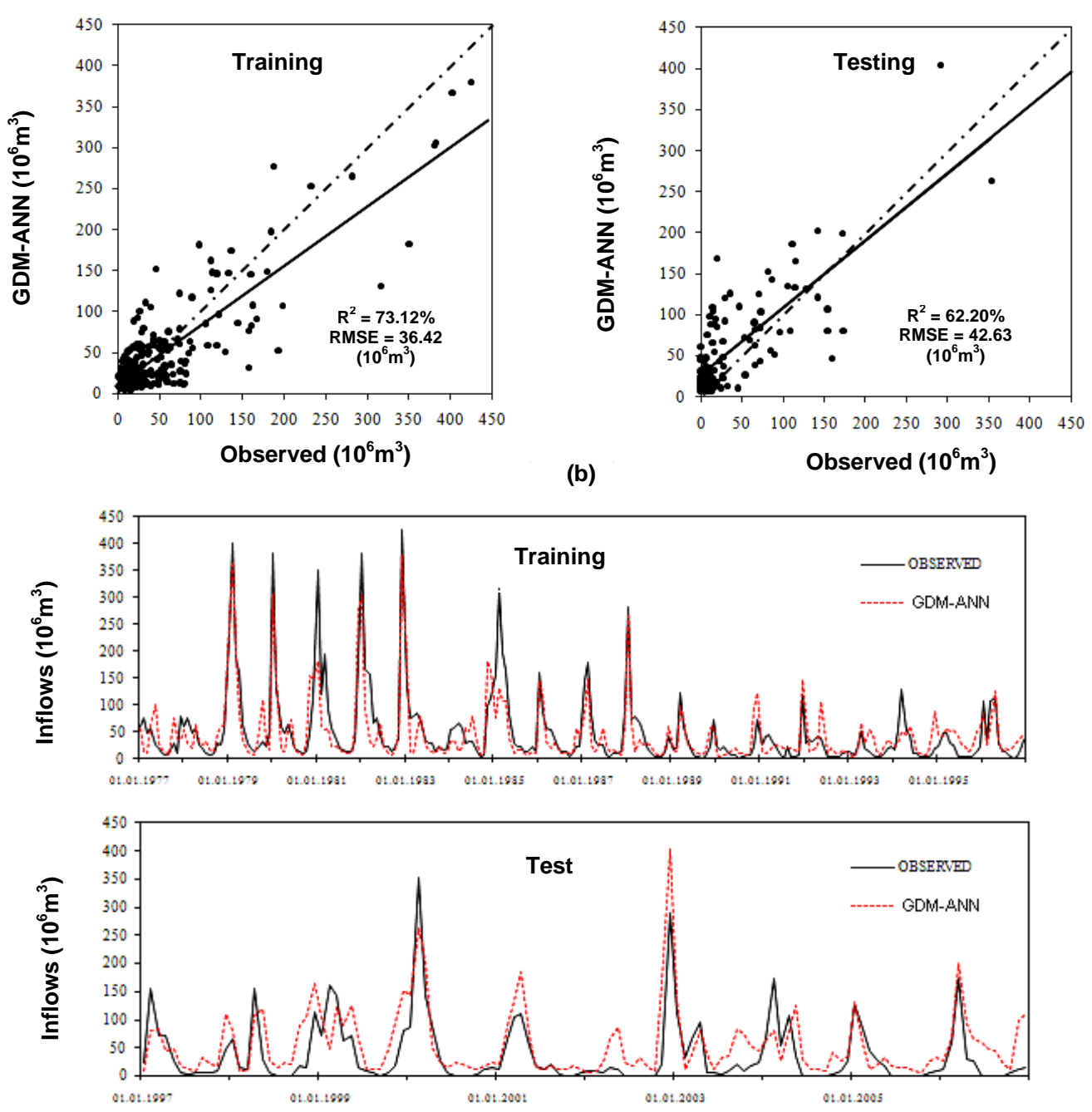

Figure 7 The scatter plots (a) and time series plots (b) of GDM-ANN model which used the concurrent rainfall, temperature and one antecedent rainfall data as input (learning rate $=0.30 ;$ momentum rate $=0.9$ )

Table 3 The Results of LM-ANN and GDM-

ANN that used the concurrent rainfall, temperature and one antecedent rainfall data as

\begin{tabular}{lcccc}
\multicolumn{5}{c}{ input } \\
Algorithm & $(\boldsymbol{k})$ & seconds & $\begin{array}{c}\mathbf{R}^{\mathbf{2}} \\
\text { (Testing) }\end{array}$ & $\begin{array}{c}\text { RMSE } \\
\text { (Testing) } \\
\mathbf{1 0}^{\mathbf{6}} \mathbf{m}^{\mathbf{3}}\end{array}$ \\
\hline $\begin{array}{l}\text { LM-ANN } \\
\text { (Model I) }\end{array}$ & 10 & 0.47 & 75.34 & 34.37 \\
GDM-ANN & 10000 & 172.35 & 62.20 & 42.63 \\
\hline
\end{tabular}

In Table 3, the iteration numbers, times (seconds), RMSE, and determination coefficients $\left(R^{2}\right)$ for testing periods are shown for each algorithm. From Table 3, it is obvious that GDM-ANN algorithm takes high number of iterations $(k)$ and time (on a PC-Pentium IV) in training process.

\section{Conclusions}

From the overall studies above, the availability of Levenberg-Marquardt algorithm based multilayer artificial neural networks for monthly inflows modeling was examined and the following evaluations were made.

- In modeling the monthly inflows with artificial neural networks, the optimum number of antecedent rainfalls constituting the input should be examined. The results of testing periods showed that correlated inputs variables $\left(R_{t}, R_{t-1}\right.$ and $\left.R_{t-3}\right)$ may reduce the performance and also the generalization capabilities of the LM-ANN.

- For the different monthly modeling studies, to improve the model performances even further, 
it may be required to use antecedent inflow values as input.

- Further, the time required for training by the LM-ANN is not only the lowest but also only a fraction of the time taken by GDM-ANN algorithms.

- This was also proved with this study, that LM-ANN is the one of the most successful black box techniques which is capable of rainfall-runoff modeling without the detailing of the physical process and can be also used for modeling of other hydrological components in terms of a rapid assessment and its robustness.

\section{References}

[1] Abbott, M.B. and Refsgaard, J.C. Distributed Hydrological Modeling. Kluver Academic Publishers, Dordrecht. 17-39 (1996).

[2] Spolia, S.K., and Chander, S. Modeling of surface runoff systems by an ARMA model. Journal of Hydrology, 22, 317-332 (1974).

[3] Sim C. H. A Mixed Gamma $\operatorname{ARMA}(1,1)$ Model for River Flow Time Series. Water Resources Research, 23(1), 32-36 (1987).

[4] Fernandez B., and Salas J.D. Gamma Autoregressive Models for Stream- Flow Simulation. Journal of Hydrologic Engineering, 116 (11), 1403-1414 (1990).

[5] Cigizoglu, K., and Bayazit, M. Application of Gamma Autoregressive Model to Analysis of Dry Periods. Journal of Hydrologic Engineering, 3(3), 218-221 (1998).

[6] Yurekli, K., and Ozturk, F. Stochastic Modeling of Annual Maximum and Minimum Streamflow of Kelkit Stream, Water International, 28, 433441 (2003).

[7] Yurekli, K., Kurunc, A., and Ozturk, F. Application of Linear Stochastic Models to Monthly Flow Data of Kelkit Stream, Ecological Modeling, 183, 67-75 (2005a).

[8] Yurekli, K., Kurunc, A., and Ozturk, F. Testing The Residuals of an ARIMA Model on The Cekerek Stream Watershed in Turkey, Turkish Journal of Engineering and Environmental Sciences, 29, 61-74 (2005b).

[9] Kurunc, A., Yurekli, K., and Cevik, O. Performance of Two Stochastic Approaches for Forecasting Water Quality and Streamflow Data from Yeşilırmak River, Turkey, Environmental Modeling \& Software, 20, 1195-1200 (2005).

[10] Raman, H. and Sunilkumar, N., Multivariate modeling of water resources time series using artificial neural networks, Hydrological Sciences Journal, 40, 2, 145-163 (1995).

[11] Hsu, K., Gupta, H.V. and Sorooshian, S., Artificial neural network modelling of the rainfall runoff process, Water Res. Research, 31, 2517-2530 (1995).

[12] Minns, A.W. and Hall, M.J., Artificial neural networks as rainfall runoff models Hydrological Sciences Journal, 41, 3, 399-417 (1996).

[13] Tokar, A.S. and Johnson, P.A., Rainfall runoff modeling using artificial neural networks, Journal of Hydrologic Engineering, 4, 3, 232-239 (1999).

[14] Cigizoglu, H.K., Incorporation of ARMA models into flow forecasting by artificial neural networks, Environmetrics, 14, 4, 417-427 (2003).

[15] Kisi, O., Daily river flow forecasting using artificial neural networks and auto-regressive models. Turkish Journal of Engineering and Environmental Sciences, 29, 9-20 (2005).

[16] Campolo, M., Andreussi, P. ve Soldati, A., River flood forecasting with a neural network model, Water Resources Research, 35, 1191-1197 (1999).

[17] Méndez, M. C., Manteiga, W.G., Bande, M.F. Sánchez J.M.P. and Calderón R.L., Modeling of the monthly and daily behavior of the runoff of the Xallas river using Box-Jenkins and neural networks methods. Journal of Hydrology, 296, 38-58 (2004).

[18] Okkan, U., Mollamahmutoğlu, A. Çoruh Nehri günlük akımlarının yapay sinir ağları ile tahmin edilmesi, Süleyman Demirel Üniversitesi Fen Bilimleri Enstitüsü Dergisi, 14, 3, 251-261 (2010a).

[19] Cigizoglu H.K., Application of the Generalized Regression Neural Networks to Intermittent Flow Forecasting and Estimation. Journal of Hydrologic Engineering, 10(4), 336-341 (2005a).

[20] Cigizoglu H.K., Generalized regression neural networks in monthly flow forecasting. Civil Engineering and Environmental Systems. 22 (2), 71-84 (2005b).

[21] Fernando, D.A.K., and Jayawardena, A.W., Runoff forecasting using RBF networks with OLS algorithm, Journal of Hydrologic Engineering 3, 3, 203-209 (1998). 
[22] Lin, G., and Chen, L., A non-linear rainfallrunoff model using radial basis function network, Journal of Hydrology, 289, 1-8 (2004).

[23] Okkan, U., Serbeş Z.A., Radyal tabanlı yapay sinir ağları yaklaşımı ile günlük akımların modellenmesi, İnşaat Mühendisleri Odası İzmir Şube Bülteni, 155, 26-29 (2010).

[24] Haykin, S. Neural Networks: A Comprehensive Foundation. MacMillan. New York (1994).

[25] Skapura, D. M. Building Neural Networks, Addison-Wesley, New York (1996)

[26] Ham, F., and Kostanic, I., Principles of Neurocomputing for Science and Engineering. Macgraw-Hill. USA (2001).

[27] Kisi, O., Multi-layer perceptrons with Levenberg-Marquardt training algorithm for suspended sediment concentration prediction and estimation. Hydrological Sciences Journal 49 (6), 1025-1040 (2004).

[28] Cigizoglu, H.K., and Kisi, O., Flow prediction by three back propagation techniques using k-fold partitioning of neural network training data. Nordic Hydrology 36 (1), 49-64 (2005).

[29] Okkan, U., Mollamahmutoğlu, A. Yiğitler Çayı günlük akımlarının yapay sinir ağları ve regresyon analizi ile modellenmesi, Dumlupınar Üniversitesi Fen Bilimleri Enstitüsü Dergisi, 23, 33-48 (2010b).

[30] Hagan, M.T., and Menhaj, M.B., Training feed forward techniques with the Marquardt algorithm. IEEE Transactions on Neural Networks 5 (6), 989-993 (1994).

[31] Marquardt, D., An algorithm for least squares estimation of non-linear parameters. Journal of the Society for Industrial and Applied Mathematics 11 (2), 431-441 (1963).

[32] Hagan, M.T., Demuth, H.P., and Beale, M. Neural Network Design. PWS Publishing, Boston (1996).
Umut OKKAN (M.Sc.) is a Research Assistant at Balikesir University - Engineering and Architecture Faculty - Department of Civil Engineering. His research interests are hydrology, water resources, climate models, statistics, stochastic modeling, artificial intelligence techniques, and designing of water distribution systems. 
